\title{
Particle shape optimization by changing from an isotropic to an anisotropic nanostructure: preparation of highly active and stable supported Pt catalysts in microemulsionst
}

\author{
Riny Y. Parapat, ${ }^{\text {*a }}$ Muliany Wijaya, ${ }^{a}$ Michael Schwarze, ${ }^{a}$ Sören Selve, ${ }^{a}$ Marc Willinger ${ }^{b}$ \\ and Reinhard Schomäcker*a
}

We recently introduced a new method to synthesize an active and stable Pt catalyst, namely thermodestabilization of microemulsions (see R. Y. Parapat, V. Parwoto, M. Schwarze, B. Zhang, D. S. Su and R. Schomäcker, J. Mater. Chem., 2012, 22 (23), 11605-11614). We are able to produce Pt nanocrystals with a small size $(2.5 \mathrm{~nm})$ of an isotropic structure i.e. truncated octahedral and deposit them well on support materials. Although we have obtained good results, the performance of the catalyst still needed to be improved and optimized. We followed the strategy to retain the small size but change the shape to an anisotropic structure of Pt nanocrystals which produces more active sites by means of a weaker reducing agent. We found that our catalysts are more active than those we reported before and even show the potential to be applied in a challenging reaction such as hydrogenation of levulinic acid.

Received 2nd August 2012 Accepted 25th November 2012

DOI: $10.1039 / c 2 n r 32122 j$

www.rsc.org/nanoscale energies corresponding to different crystallographic facets usually increase in the order $\gamma_{\{111\}}<\gamma_{\{100\}} \ll \gamma_{\{110\}} \ll \gamma_{\{h k l}$, where $\{h k l\}$ represents high-index facets, with at least one $h, k$, and $l$ equal to two or greater. ${ }^{8}$ Although the synthesis of nanocrystals with high-index surfaces was achieved by some groups, the size of the crystals is still rather high (20$240 \mathrm{~nm}){ }^{9,10}$ More important for catalysis, shape control with precision at a scale smaller than $10 \mathrm{~nm}$ effectively engineers the chemical surface of the nanoparticle. ${ }^{9}$ Therefore the formation of small nanoparticles with high index facets remains challenging.

To produce nanoparticles which have high-index planes, the preferred growth direction during synthesis is anisotropic growth. It can be induced by employing surfactants which can bind preferentially to crystal faces of the growing particles. ${ }^{10,11}$ In our previous work, we were able to prepare multifaceted Pt nanoparticles and we concluded that the shape is dominantly influenced by the surfactant. ${ }^{11,12}$ However, this account is appropriate probably only in the case of using a strong reducing agent. We used a strong reducing agent, hydrazine, to make sure that the reduction process will be faster and thus not contribute in regulating the shape. However, the anisotropic growth can also be promoted by a very slow reduction rate at room temperature and the lowest energy principle. ${ }^{13}$ The slow reduction rate of the metal precursor can be carried out by means of a weak reducing agent. A weak reducing agent effectively isolates the nucleation and growth events allowing control over the size and shape. ${ }^{14,15}$ This statement is also confirmed by some published results which show that some
${ }^{a}$ Technische Universität Berlin, Strasse des 17. Juni 124, 10623 Berlin, Germany. E-mail: rinyyolandha@mailbox.tu-berlin.de; schomaecker@tu-berlin.de

${ }^{b}$ Fritz Haber Institute of the Max Plank Society, Faradayweg 4-6, 14195 Berlin, Germany

† Electronic supplementary information (ESI) available. See DOI: $10.1039 / \mathrm{c} 2 \mathrm{nr} 32122 \mathrm{j}$ 
weak reducing agents such as formic acid and ascorbic acid are effective for producing anisotropic platinum nanostructures. ${ }^{13,16-18}$ Pillai and Subhramannia reported that when $\mathrm{NaBH}_{4}$ is replaced by $\mathrm{HCOOH}$, nanoflowers comprised of large quantities of nanowires are obtained. ${ }^{4}$ Chen et al. reported that by slowing the reduction rate (extremely low supersaturations) of Pt salts, only highly anisotropic Pt nanostructures were formed. In contrast, if the reduction proceeded too fast (the supersaturation was too high) only isotropic Pt nanoparticles were produced..$^{19}$

Despite the high activity of complex anisotropic nanostructures, generally they are still produced in a colloidal state which is thermodynamically unstable. ${ }^{9}$ Moreover, the use of capping agents in colloidal systems in most cases hinders or even prevents catalysis by blocking some of their active sites and also through inducing steric effects. ${ }^{4}$ As a matter of fact, when our Pt particles in a microemulsion-based suspension were tested catalytically in hydrogenation of $\alpha$-methyl styrene, the activity was very poor compared with its supported counterparts. The same observations are also obtained by Boutonnet et al. ${ }^{20}$ Therefore, it is far better to have a stable state and an unhindered contact between the substrates and active sites of the metal. An alternative approach is to stabilize the metal particles by dispersing them on a support. However, it is often difficult to obtain a good dispersion while preserving the size and shape of nanoparticles during the deposition process. ${ }^{12,21}$ The dispersion of nanoparticles on the support is significant because it affects the catalyst performance. This difficult challenge however has been overcome in our method, namely thermo-destabilization of microemulsions.

In our recent study, we presented a new method to synthesize active and stable supported Pt catalysts. ${ }^{12}$ There are several major parameters that determine the size, shape and dispersion of metal on the support which influence the catalyst performance such as the concentration of surfactant and oil, concentration of precursors, heating rate during destabilization, kind of support, etc. In order to improve the activity of our Pt catalysts, we decided to modify the shape of the $\mathrm{Pt}$ particles by changing the reducing agent and the $\mathrm{Pt}$ precursor.

Because the comprehensive study of our synthesis method has been reported in our previous paper, here we are focusing more on optimizing the performance of supported Pt catalysts by improving the surface energy of nanoparticles rather than comparing with other synthesis methods. In this study, we improve the catalytic activity mostly by means of a weak reducing agent (ascorbic acid). Combinations of the use of a weak reducing agent to create an anisotropic nanostructure and the deposition with the thermo-destabilization of microemulsions method are potentially promising for increasing the activity of supported metal catalysts.

To elucidate whether this synthesis method is a viable strategy, we also tested the catalytic activity of our supported Pt catalysts in some reactions such as hydrogenation of methyl crotonate, itaconic acid and levulinic acid. However, the results are discussed only briefly in this paper.

\section{Experimental section}

\subsection{Materials}

The chemicals used in the preparation of Pt nanoparticles were the following: hexachloroplatinic acid hydrate (99.9\%, SigmaAldrich) and potassium tetrachloro-platinate(II) (99.9\%, SigmaAldrich) as platinum precursors; hydrazine monohydrate (98\%, Sigma-Aldrich) and L-(+)-ascorbic acid (>99\%, Alfa Aesar) as reducing agents, cyclohexane $(\geq 99.5 \%$, Carl-Roth) as oil phase, 1-pentanol ( $\geq 98 \%$, Carl-Roth) as co-surfactant, and Triton X-100 (100\%, Sigma-Aldrich) as surfactant. All the chemicals above were used without further purification. The support materials used were (base, neutral and acid) $-\mathrm{Al}_{2} \mathrm{O}_{3}$ (SigmaAldrich), $\mathrm{SiO}_{2}$ (Sigma-Aldrich), Sipernat 310 (Evonik) and selfprepared SBA-15 according to the method reported by Zhao et $a .^{22}$ All supports were pre-calcined before use. For the washing of the catalysts after the synthesis, acetone $(\geq 99.8 \%$, Carl Roth) was used. The chemicals used for the hydrogenation reactions: methanol ( $\geq 99.9 \%$, Carl Roth) as solvent; $\alpha$-methyl styrene (99\%, Aldrich), methyl crotonate (99\%, Sigma-Aldrich), itaconic acid (99\%, Sigma-Aldrich) and levulinic acid (98\%, Sigma-Aldrich) as reactants; all were used as received.

\subsection{Catalyst preparation}

Phase behaviour of microemulsion systems. For the determination of the deposition temperature, the phase diagram of a microemulsion needs to be established. The principle and the stepwise preparation of phase diagrams have been described in the previous paper. ${ }^{12}$

Synthesis of nanoparticles and deposition process. The typical synthesis using microemulsion systems for preparing Pt nanoparticles comprises the water phase either with metal salts $\left(\mathrm{H}_{2} \mathrm{PtCl}_{6}\right.$ and $\left.\mathrm{K}_{2} \mathrm{PtCl}_{4}\right)$ or reductants (hydrazine and ascorbic acid), Triton $\mathrm{X}-100$ as the surfactant, pentanol as the cosurfactant and cyclohexane as the oil phase. The mass fraction of oil in the microemulsion system is defined by $\alpha=m_{\mathrm{o}} /\left(m_{\mathrm{o}}+\right.$ $\left.m_{\mathrm{w}}\right)$, whereas the mass fraction of surfactant and co-surfactant is defined by $\gamma=\left(m_{\mathrm{s}}+m_{\text {co-s }}\right) /\left(m_{\mathrm{s}}+m_{\text {co-s }}+m_{\mathrm{o}}+m_{\mathrm{w}}\right)$. The mass ratio of co-surfactant to surfactant is defined by $\delta$. The values of $\alpha, \gamma$ and $\delta$ used in this study are $0.75,0.4$ and 1 , respectively. The metal salts and reductants are then prepared in different concentrations. The reactions that occur during the mixing of microemulsions (collision of the reverse micelles) for different syntheses according to the kind of metal salt and the reducing agent are the following:

$$
\begin{gathered}
\mathrm{H}_{2} \mathrm{PtCl}_{6}+\mathrm{N}_{2} \mathrm{H}_{4} \rightarrow \mathrm{Pt}^{0}+6 \mathrm{HCl}+\mathrm{N}_{2} \\
\mathrm{H}_{2} \mathrm{PtCl}_{6}+2 \mathrm{C}_{6} \mathrm{H}_{8} \mathrm{O}_{6} \rightarrow \mathrm{Pt}^{0}+2 \mathrm{C}_{6} \mathrm{H}_{6} \mathrm{O}_{6}+6 \mathrm{HCl} \\
\mathrm{K}_{2} \mathrm{PtCl}_{4}+\mathrm{C}_{6} \mathrm{H}_{8} \mathrm{O}_{6} \rightarrow \mathrm{Pt}^{0}+\mathrm{C}_{6} \mathrm{H}_{6} \mathrm{O}_{6}+2 \mathrm{KCl}+2 \mathrm{HCl}
\end{gathered}
$$

The microemulsions were mixed according to the calculated values of $\alpha, \gamma$ and $\delta$. The synthesis of the platinum nanoparticles was carried out at $25{ }^{\circ} \mathrm{C}$ in a $200 \mathrm{ml}$ double-wall glass reactor equipped with a double parallel three-blade impeller. The 
hydrazine microemulsion was added slowly to the reactor, which had already been filled with the Pt salt microemulsion, by a micro-pump at a rate of $0.2 \mathrm{ml} \mathrm{s}^{-1}$. The mixture was stirred at $700 \mathrm{rpm}$ for 30 minutes (with $\mathrm{N}_{2} \mathrm{H}_{4}$ ) or 2 hours (with AA) respectively at room temperature to form colloidal stabilized $\mathrm{Pt}$ nanoparticles. Then the pre-calcined support $\left(500{ }^{\circ} \mathrm{C}\right.$ for 2 hours) was added to the mixture, and the Pt nanoparticles were deposited on the support material by heating the microemulsion to $46{ }^{\circ} \mathrm{C}$, at a heating rate of $1{ }^{\circ} \mathrm{C} \mathrm{min}{ }^{-1}$. After the deposition process, the mixture was cooled down. After all the supported catalysts precipitated, they were carefully separated from the solution and washed three times with pure acetone. Consistent with prior work, calcination was carried out at 300 ${ }^{\circ} \mathrm{C}$ for 2 hours to avoid the shape modification of metal nanoparticles.

Activity testing in hydrogenation reaction. Hydrogenation of AMS was performed over the $\mathrm{Pt} / \mathrm{Al}_{2} \mathrm{O}_{3}$ catalysts to expound the effect of particle morphology on the catalytic activity. The activity testing in hydrogenation reaction has been described in the previous paper. Details of the procedure are given in the ESI. $†$

Characterization and analysis methods. The shape, size, and lattice structure of the Pt nanoparticles were investigated with a transmission electron microscope (TEM) at an FEI Titan 80-300 (sub-Angstrom resolution, able to investigate at atomic scale), and also with a FEI Tecnai $G^{2} 20$ S-Twin TEM and Philips CM200/FEG high-resolution TEM (HRTEM) operated at $200 \mathrm{kV}$. Both microscopes are equipped with an energy dispersive X-ray detector (EDX). The TEM grids were prepared for imaging by placing a small drop of the specimen solution on a copper grid having an amorphous carbon film less than $20 \mathrm{~nm}$ thick and allowing it to dry completely in air at ambient temperature. The Pt content of the support catalysts was analyzed with an ICPOES Element 2 (Varian) at low resolution (sample gas $0.863 \mathrm{~L}$ $\mathrm{min}^{-1}$; plasma power $1350 \mathrm{~W}$ ). The effective surface charges ( $\zeta$-potential) on the $\mathrm{Pt}$ nanoparticles and alumina support material were measured using zeta-potential Zen 3600 (Malvern Instruments Zetasizer, Worcestershire, UK) equipment, with samples thermostated at $25^{\circ} \mathrm{C}$. The specific surface areas of the catalysts were measured via the BET method using $\mathrm{N}_{2}$ adsorption at liquid $\mathrm{N}_{2}$ temperature in a Micromeritics Gemini III 237 Volumetric Surface Analyzer. The sample was outgassed at $200{ }^{\circ} \mathrm{C}$ for $1 \mathrm{~h}$ in order to desorb any impurities or moisture from its surface.

\section{Results and discussion}

\subsection{Effect of reducing agent on catalytic activity}

As we already mentioned, with our previous result we are able to produce truncated octahedron Pt nanocrystals in the microemulsions system by using hydrazine as the reductant. To see whether the reducing agent affected the morphology of the produced Pt particles, we used ascorbic acid (AA) as the reductant, to induce a slower reducing process. The result is illustrated in Fig. 1. The TEM images show the Pt particle with hexagonal form (upper) after reduction with hydrazine and the dendritic form (bottom) after reduction with ascorbic acid. This confirms what we have previously described, that when using a weaker reducing agent in the microemulsion based synthesis, the shape of the nanoparticles is strongly affected by the reducing agent rather than by the surfactant. In fact, Shen et al. still produce dendritic Pt nanostructures while using four different surfactants in a sonoelectrochemical method. ${ }^{23}$ Wang et al., without using any surfactant, cannot synthesize nanodendrite Pt nanostructures by using hydrazine or $\mathrm{NaBH}_{4}$, but they can produce them by using ascorbic acid as the reducing agent. ${ }^{16}$ Unfortunately, because they do not use a capping agent, they produce polydispersed Pt nanodendrites $(20-70 \mathrm{~nm})$. They also reported that a byproduct of Pt reduction by AA, diketo-Lgulonic acid (DGA), serves as a shape-directing agent to direct the branched growth. ${ }^{16}$ The mechanism of the growth of branches seems to involve controlled, epitaxial growth from the surface of a particle. ${ }^{24}$

In contrast to AA, although hydrazine was found to be the best reducing agent because the particle distribution was optimal when compared with the one obtained for metals reduced with $\mathrm{NaBH}_{4}, \mathrm{H}_{2}$ or other reducing agents, ${ }^{25}$ it cannot promote the anisotropic growth. Moreover, it was observed for some cases that the remaining hydrazine behaved as a poison for the catalyst. ${ }^{25}$ Therefore, it can be concluded that in this case using AA as a reductant is more favorable.

\subsection{Structure of Pt nanodendrites in reverse micelles}

Fig. 2 shows the detailed structure of Pt nanodendrites that are composed of irregular shaped arms as portrayed in Fig. 2A and B. This anisotropic growth is favored by a slow reduction process and relatively low temperature of synthesis $\left(25^{\circ} \mathrm{C}\right) \cdot{ }^{24,26}$ Fig. 2A and B show the Pt dendrites produced with surfactant (in the reverse micelle) and without surfactant, respectively, with the same concentrations of Pt ions and reductant. The Pt dendrite in Fig. 2A looks smaller than that in Fig. 2B because the surfactant restricts the growth. Also, due to the relatively low concentration of $\mathrm{H}_{2} \mathrm{PtCl}_{6}$ inside the reverse micelles, only a few branches of Pt nanodendrites can be produced. The branches seem to be not attached to one another because when the sample was exposed to the high voltage electron beams during TEM analysis, they were separated. This might also signify that this structure is not mature yet. However the branch consists of high index planes as depicted in a detailed structured in the HRTEM image (Fig. 2C) and the corresponding fast Fourier transform (FFT) of the atomic lattice (Fig. 2D). The electron diffraction pattern is indexed to the $\{111\},\{200\},\{220\},\{311\}$, $\{331\}$ and $\{511\}$ diffractions, respectively.

As stated above, the thermodynamic equilibrium shape of $\mathrm{Pt}$ particles produced when using hydrazine as the reductant is truncated octahedron. This regular crystallite is composed of the lowest-index crystal planes $\{111\}$ and $\{100\}$, which are known to be the least active. The irregular polycrystalline structure produced with AA, Pt nanodendrite, is our expected result because it is composed of the higher index crystal planes especially $\{311\},\{331\}$ and $\{511\}$. The high index planes exhibit much higher reactivity because of the low coordination number and high density of atomic steps, ledges and kinks, which 


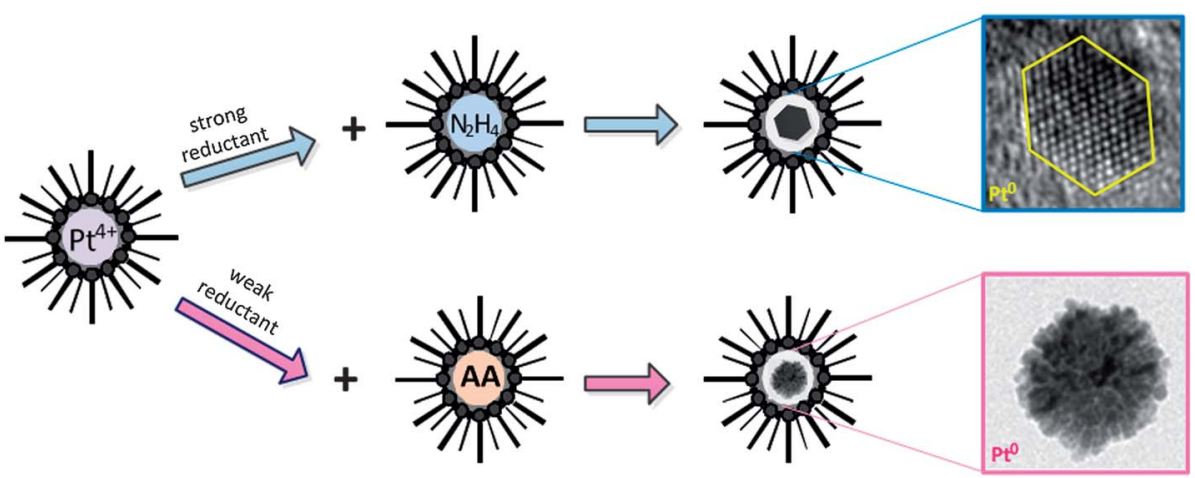

Fig. 1 Illustration of the role of the reducing agent to produce different shapes of Pt nanoparticles.
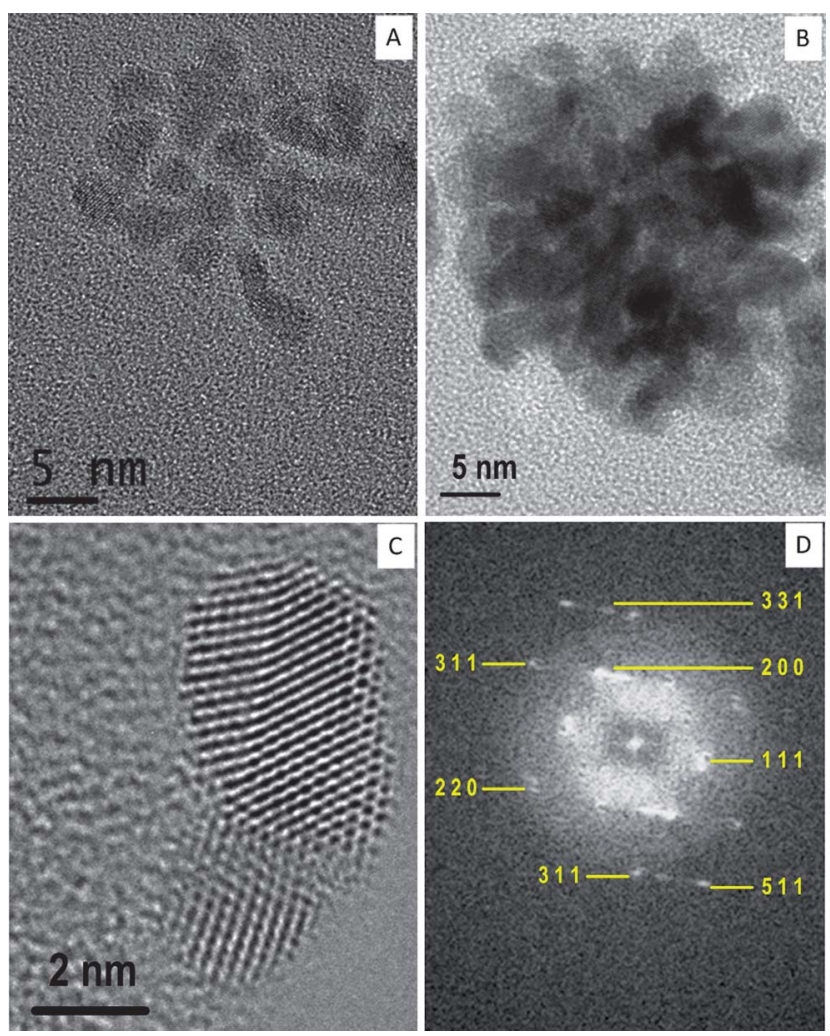

Fig. 2 Pt clusters produced with ascorbic acid as a reductant in the presence of the surfactant (A), in the absence of the surfactant (B), HRTEM of a branch of Pt dendrite (C), and its fast Fourier transform (FFT) with the lattice indexes (D).

usually serve as active sites for breaking chemical bonds. ${ }^{4}$ This is confirmed by Fig. 3 that shows the higher activity of supported Pt nanodendrite catalysts compared to that of Pt truncated octahedron. Hence, the irregular structure of nanodendrites provides more active sites than the truncated octahedron.

\subsection{Effect of support acidity on catalytic activity}

We also observe that the support acidity affects the activity of the Pt catalyst (Fig. 3 and Table 1). Note that we used the acidic, neutral and basic $\mathrm{Al}_{2} \mathrm{O}_{3}$ which are commercially available. The lowest activity of the Pt nanodendrite deposited on basic $\mathrm{Al}_{2} \mathrm{O}_{3}$ can be explained as follows. For Pt particles which are reduced with ascorbic acid, the microemulsions containing Pt particles are acidic $(\mathrm{pH} \approx 4)$. Therefore, they tend to destabilize quickly when they are around the basic $\mathrm{Al}_{2} \mathrm{O}_{3}$ and $\mathrm{Pt}$ particles agglomerate before deposition, whereas on acidic $\mathrm{Al}_{2} \mathrm{O}_{3}$ the catalyst shows higher activity because the particles are more stable before attaching to the support material. In contrast, for Pt particles which are reduced with hydrazine, the microemulsions containing Pt nanoparticles are alkaline $(\mathrm{pH} \approx 9)$. Consequently, the particles tend to agglomerate before deposition when surrounded by the acidic $\mathrm{Al}_{2} \mathrm{O}_{3}$ and be more stable when in contact with basic $\mathrm{Al}_{2} \mathrm{O}_{3}$.

The TEM images in Fig. 3 show the clear particle size distributions but they cannot give accurate dispersions because they show the particles at the outer and inner surfaces of the support. For this reason, we confirm them with SEM images which show the dispersion of the particles on the outer surface (the particle is shown in white color). From the TEM images, we can see that there is only a little Pt particle agglomeration on acidic alumina compared to the neutral and basic alumina, as pointed out by the small arrows. A dark field image (the inset of Fig. 3B, middle centre) is presented to clearly show the dispersion of Pt particles on the neutral alumina. The Pt dispersion at acidic and neutral alumina looks similar in the SEM images. Interestingly, in the case of Pt on the basic alumina, the outer particles are quite few and widely scattered. This looks contrary to its TEM image (middle right) which shows that the particles are rather dense. We note that the TEM and SEM images were not taken from the same place. This may indicate that $\mathrm{Pt}$ particles on the basic alumina are not well distributed. Hence, these visual observations are congruent with the catalytic activities because better dispersion leads to higher activity.

To validate the visual observations, we quantify the dispersion by using the Delaunay network method ${ }^{27}$ based on the TEM images in Fig. 3. In this case, we do not use SEM images because of their low magnifications, which is normal in a SEM investigation. The detail of the Delaunay network method is described in the ESI. $†$ As we can see in Fig. 3B (upper right), according to this method, the dispersions of Pt particles on the acidic, neutral and basic alumina are in the areas of good, random like and poor, respectively. These quantified results support the 

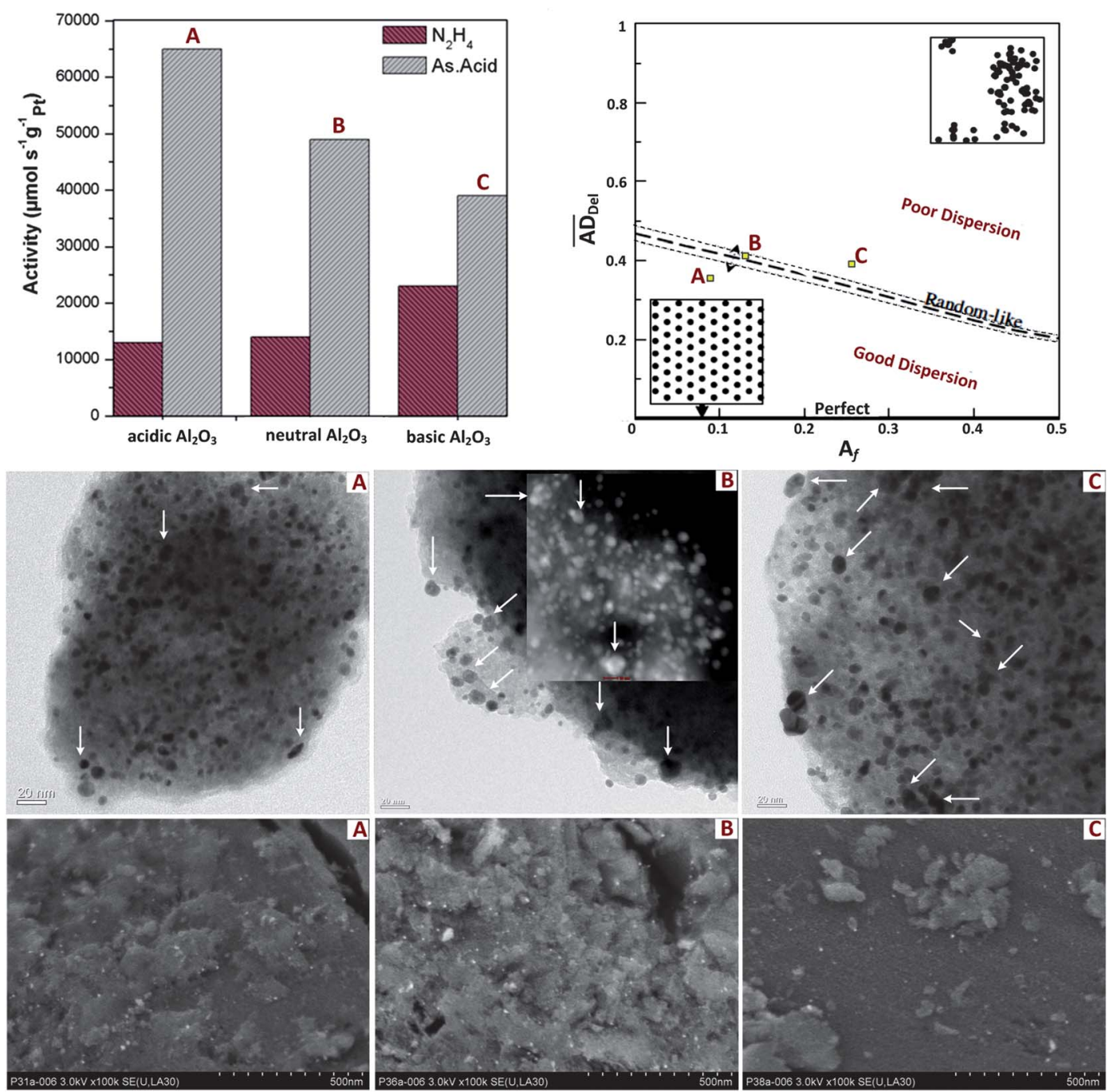

Fig. 3 Upper left: activities of Pt catalysts reduced with either hydrazine or AA and deposited on acidic (A), neutral (B), and basic (C) alumina supports. Upper right: degrees of dispersion of the corresponding catalysts with the Delaunay network method. ${ }^{27}$ Original diagram is reprinted with permission from Springer Science +Business Media B.V. Middle and bottom are the TEM and SEM images of the corresponding catalysts respectively.

visual observations and certainly agree with the catalytic activities.

To verify our observations, we also investigated the interaction between the Pt particles and the support material by measuring their zeta potentials. As we can see in Table 1 , the zeta potential of the platinum nanodendrites is about $-25 \mathrm{mV}$ whereas the zeta potentials of acidic, neutral and basic $\mathrm{Al}_{2} \mathrm{O}_{3}$ are $+45,+40$ and $+10 \mathrm{mV}$ respectively. The more positively charged support particles are more likely to interact with the negatively charged metal particles which can result in better dispersion. Therefore, the dispersion of $\mathrm{Pt}$ nanodendrites seems to be better on acidic $\mathrm{Al}_{2} \mathrm{O}_{3}$ followed by neutral $\mathrm{Al}_{2} \mathrm{O}_{3}$ and basic $\mathrm{Al}_{2} \mathrm{O}_{3}$

Table 1 Activities of 0.1 wt\% supported Pt catalysts prepared with different molar ratios of Pt to AA

\begin{tabular}{|c|c|c|c|c|}
\hline Support material & $\begin{array}{l}\zeta \text {-Potential of } \\
\text { support }^{a}(\mathrm{mV})\end{array}$ & $\begin{array}{l}\text { Molar ratio } \\
{[\mathrm{Pt}]:[\mathrm{AA}]}\end{array}$ & $\begin{array}{l}\zeta \text {-Potential } \\
\text { of Pt NPs }(\mathrm{mV})\end{array}$ & $\begin{array}{l}\text { Pt activity } \\
\left(\mathrm{mol} \mathrm{s}^{-1} \mathrm{~g}_{\mathrm{Pt}}^{-1}\right)\end{array}$ \\
\hline \multirow[t]{2}{*}{ Acidic- $\mathrm{Al}_{2} \mathrm{O}_{3}$} & \multirow[t]{2}{*}{+45} & $1: 25$ & -24.9 & 11000 \\
\hline & & $1: 50$ & -25.4 & 65000 \\
\hline \multirow[t]{2}{*}{ Neutral- $\mathrm{Al}_{2} \mathrm{O}_{3}$} & \multirow[t]{2}{*}{+40} & $1: 25$ & -24.9 & 9000 \\
\hline & & $1: 50$ & -25.4 & 49000 \\
\hline \multirow[t]{2}{*}{ Basic- $\mathrm{Al}_{2} \mathrm{O}_{3}$} & \multirow[t]{2}{*}{+10} & $1: 25$ & -24.9 & 7000 \\
\hline & & $1: 50$ & -25.4 & 29000 \\
\hline
\end{tabular}

${ }^{a}$ Experimentally measured at $\mathrm{pH}=4$, that is the average $\mathrm{pH}$ of the prepared microemulsion containing Pt nanodendrites. 
which results in an activity decrease of Pt catalysts with the support material ranking from acidic to basic $\mathrm{Al}_{2} \mathrm{O}_{3}$.

\subsection{Effect of $\mathrm{pH}$ on the structure of nanodendrites}

It is interesting to see that when we double the initial concentration of ascorbic acid, the activity of the Pt catalyst increases (Table 1). The increase of catalytic activity can be explained by the following. According to Nernst equation, the higher the $\mathrm{pH}$, the more negative the redox potential $\left(E_{\mathrm{h}}\right)$ will be and the stronger the reducing power.

$$
E_{\mathrm{h}}=E_{0} \frac{0.05916}{2} \log \frac{[\mathrm{DHA}]}{[\mathrm{AA}]}-\frac{0.05916}{2} \mathrm{pH}
$$

Hence, increasing the concentration of AA (lower $\mathrm{pH}$ ) will lower the reducing power of AA and therefore slow down the reduction process of $\mathrm{Pt}$. Consequently, this will promote the anisotropic growth of Pt nanodendrites which results in more complex structures (more edge and corner sites), thus leading to the higher activity. On the other hand, slow reduction of Pt will also lead to bigger particle size ${ }^{12}$ as confirmed by the TEM image (right) in Fig. 4 that shows bigger Pt particles produced with more AA (the particle sizes produced with Pt to AA ratios of $1: 25$ and $1: 50$ are $4.6 \pm 1.2 \mathrm{~nm}$ and $7.7 \pm 2.6 \mathrm{~nm}$, respectively). However, as we already know, the reduction of Pt takes place inside the reverse micelles, which, in turn, can limit the growth of the metal cluster. Hence, the effect of the reducing agent might be restricted.

Therefore, this phenomenon indicates that, to such an extent, the shape of complex structure Pt nanodendrites seems to have a greater influence on the activity than the particle size. This phenomenon is also observed in our previously published results which show that increasing the concentration of hydrazine (higher $\mathrm{pH}$ ) will increase its reducing power which promotes a fast reduction of Pt ions. Faster reduction of Pt ions will produce smaller particles, thus leading to higher activity of the Pt catalyst. ${ }^{12}$ In addition, the influence of $\mathrm{pH}$ on the structure of the obtained Pt nanoparticles is also reported by Ji et al. and Lee et $a .^{28,29}$

More interestingly, when we increase the initial molar ratio of Pt to AA and then deposit the produced particles on SBA-15, a different trend is observed (Fig. 5). The aforementioned results demonstrate that increasing the initial molar ratio of Pt to AA leads to bigger particles. On the other hand, the bigger particles (more than $10 \mathrm{~nm}$ ) cannot get into the pores of SBA-15. In the case of Pt supported on SBA-15, the particle size produced with [Pt] : [AA] of $1: 25$ is less than $10 \mathrm{~nm}$ whereas with $1: 50$ is greater than $10 \mathrm{~nm}$ (inset in Fig. 5). This is consistent with previous results which are shown in Fig. 4. Unfortunately, we

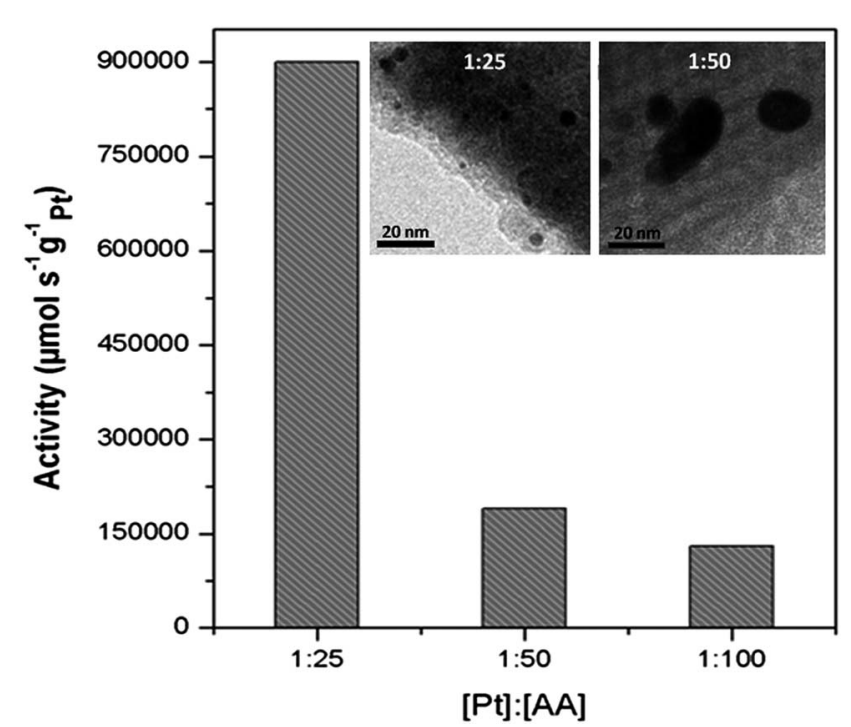

Fig. 5 Activities of the Pt nanodendrites deposited on SBA-prepared in different molar ratio Pt to AA and the corresponding TEM images (inset).
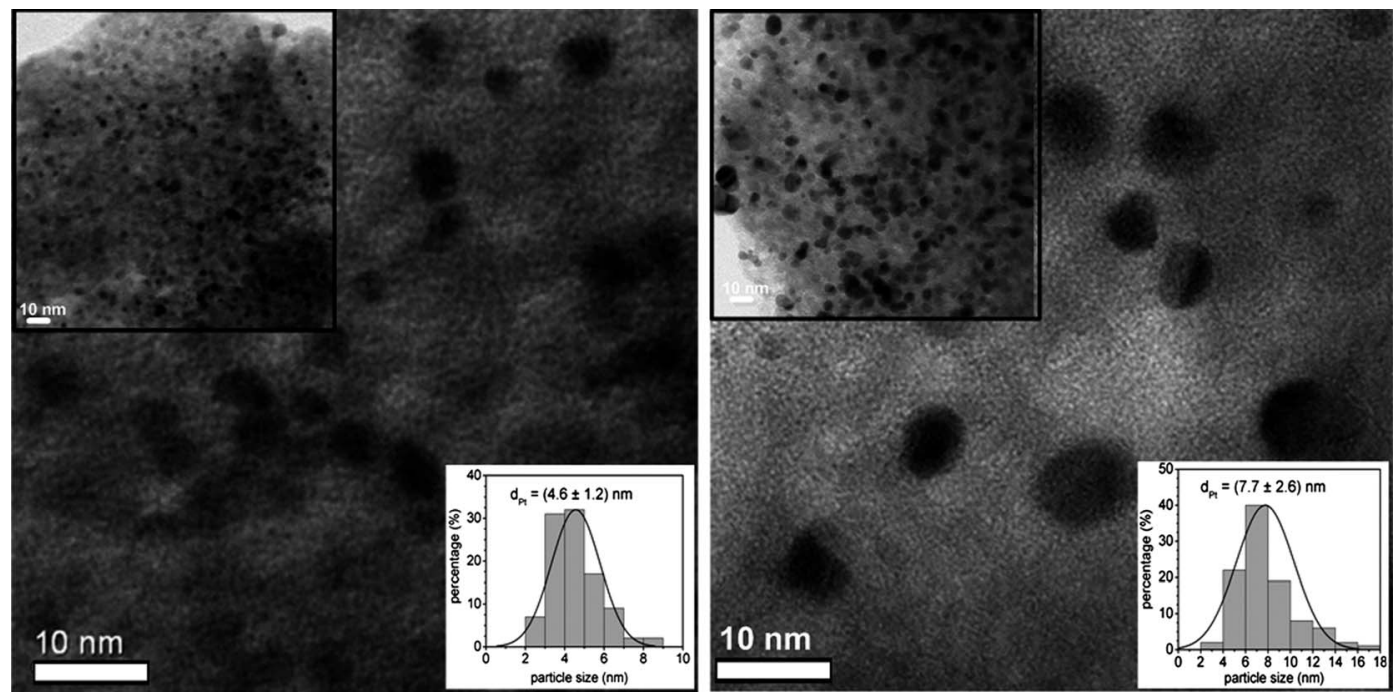

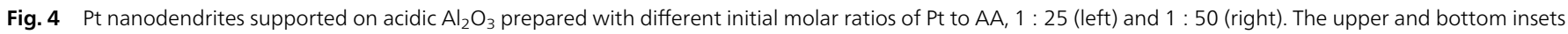
are the corresponding TEM images with low magnification and the particle size distributions (100 particles were counted). 
have no data for 1:100 but as previously hypothesized, the particles are expected to be bigger. The decrease of Pt activity shown in Fig. 5 indicates that the bigger Pt particles produced from initial ratios of $\mathrm{Pt}$ to AA of $1: 50$ and $1: 100$ are unable to spread well over SBA-15 and penetrate into the pores, and even might have a tendency to agglomerate.

It is observed that the dispersion of Pt particles on the support is significantly more homogeneous with alumina (Fig. 6c and d) than with SBA-15 (Fig. 6a and b), particularly in the sample containing small particles. We attribute this to the value of the zeta potential of SBA-15 (approx. -20) which is almost the same as Pt nanoparticles (approx. -25). This observation is in good accordance with results published by Barkhuizen et al. $^{21}$ Interestingly, although the $\mathrm{Pt}$ particles produced with hydrazine are smaller and better in distribution on the support, their activities are lower than those prepared with AA. To emphasize again, the anisotropic structure of the irregular polycrystalline Pt nanodendrites provides more active sites than the surface of a regular crystalline and therefore is the reason for the higher activities of the catalysts. Hence, as previously discussed in Section 3.4, in our case, the shape of the particles is more significant in affecting the activity of the catalyst than the particle size despite bigger size and poor arrangement. This fact shows that the strategy of "making things smaller and smaller" - which is nowadays the strategy followed by many scientists - does not always lead to catalysts with better properties.

\subsection{Effect of metal precursor on catalytic activity}

The activity was further optimized, when the metal precursor was replaced by $\mathrm{K}_{2} \mathrm{PtCl}_{4}$, and a significant improvement of activity was observed. We attribute this to the fact that it is easier for $\mathrm{AA}$ to reduce the $\mathrm{Pt}^{2+}$ ion to $\mathrm{Pt}^{0}$ rather than $\mathrm{Pt}^{4+}$, which leads to more formation of dendritic branches. In addition, Duff et al. reported that the reduction of $\mathrm{PtCl}_{4}{ }^{2-}$ proceeds much faster than of $\mathrm{PtCl}_{6}{ }^{2-} \cdot{ }^{30}$ As a result, the particles that are produced from $\mathrm{PtCl}_{4}{ }^{2-}$ are smaller but higher in number than those from $\mathrm{PtCl}_{6}{ }^{2-}$. This is confirmed by HRTEM images (insets) in the bottom part of Fig. 7 which show the corresponding Pt dendrites in the reverse micelles with different magnifications. According to our observation in TEM investigations, during the transmission, the high voltage electron beams from the TEM filament affected the original structure of the Pt dendrites which caused separation and movement of the branches on the carbon grid. However, we can still see that the branches of Pt dendrites produced by $\mathrm{K}_{2} \mathrm{PtCl}_{4}$ are smaller than those by $\mathrm{H}_{2} \mathrm{PtCl}_{6}$.

Duff et al. also suggested that the chloride ions play a determining role in the shape of Pt particles. In this case, although the greater amount of chloride ions present in the solutions will cause the slower reduction process, they do not promote the anisotropic growth. Instead, they limit the nucleation, hinder the combination of growing clusters, and as a result promote regular growth (isotropic) forms. By this hypothesis, it can be assumed that the increase of $\mathrm{Cl}^{-}$ions could retard the formation of the anisotropic structures of $\mathrm{Pt}$ nanodendrites. Therefore, the shape of $\mathrm{Pt}$ nanodendrites produced from $\mathrm{K}_{2} \mathrm{PtCl}_{4}$ is more irregular than those from $\mathrm{H}_{2} \mathrm{PtCl}_{6}$ and thus provides more active sites.

Here, we also propose that the different ligands and counter ions of $\mathrm{H}_{2} \mathrm{PtCl}_{6}$ and $\mathrm{K}_{2} \mathrm{PtCl}_{4}$ also contribute to the dendritic growth mechanism which causes the different structures of $\mathrm{Pt}$ dendrites. Ciacchi et al. reported that the structure of $\mathrm{Pt}^{2+}$ complexes and the ligands influence the mechanism of metal cluster growth. ${ }^{31,32} \mathrm{H}_{2} \mathrm{PtCl}_{6}$ is known to undergo a series of hydrolysis reactions in aqueous solutions leading to the formation of $\left.\mathrm{PtCl}_{6-x}\left(\mathrm{H}_{2} \mathrm{O}\right)_{x}\right]^{x-2}$ complexes, ${ }^{33}$ while the octahedral coordination of $\mathrm{Pt}(\mathrm{Iv})$ remains intact. ${ }^{34}$ The planar square $\mathrm{PtCl}_{4}{ }^{2-}$ complex produced from $\mathrm{K}_{2} \mathrm{PtCl}_{4}$ also undergoes hydrolysis leading to the formation of $\left.\mathrm{PtCl}_{4-x}\left(\mathrm{H}_{2} \mathrm{O}\right)_{x}\right]^{x-2}$ complexes. ${ }^{31,35}$ Siani et al. reported that the reduction mechanisms of these Pt complexes are different. Therefore, it can be speculated that the planar square $\mathrm{Pt}^{2+}$ structure and the octahedral $\mathrm{Pt}^{4+}$ structure can influence the final shape of the produced nanoparticle. Yao et al. describe that when $\mathrm{Pt}^{2+}$ is
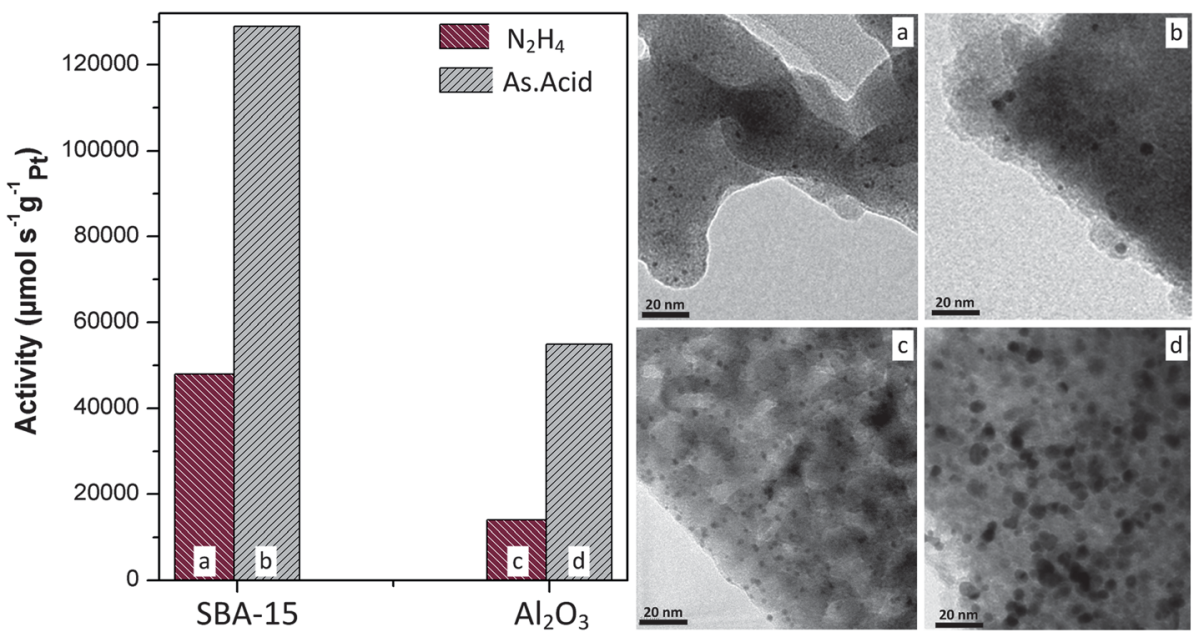

Fig. 6 Activities of the supported Pt catalysts prepared with hydrazine and ascorbic acid as reductants and the corresponding TEM images. 

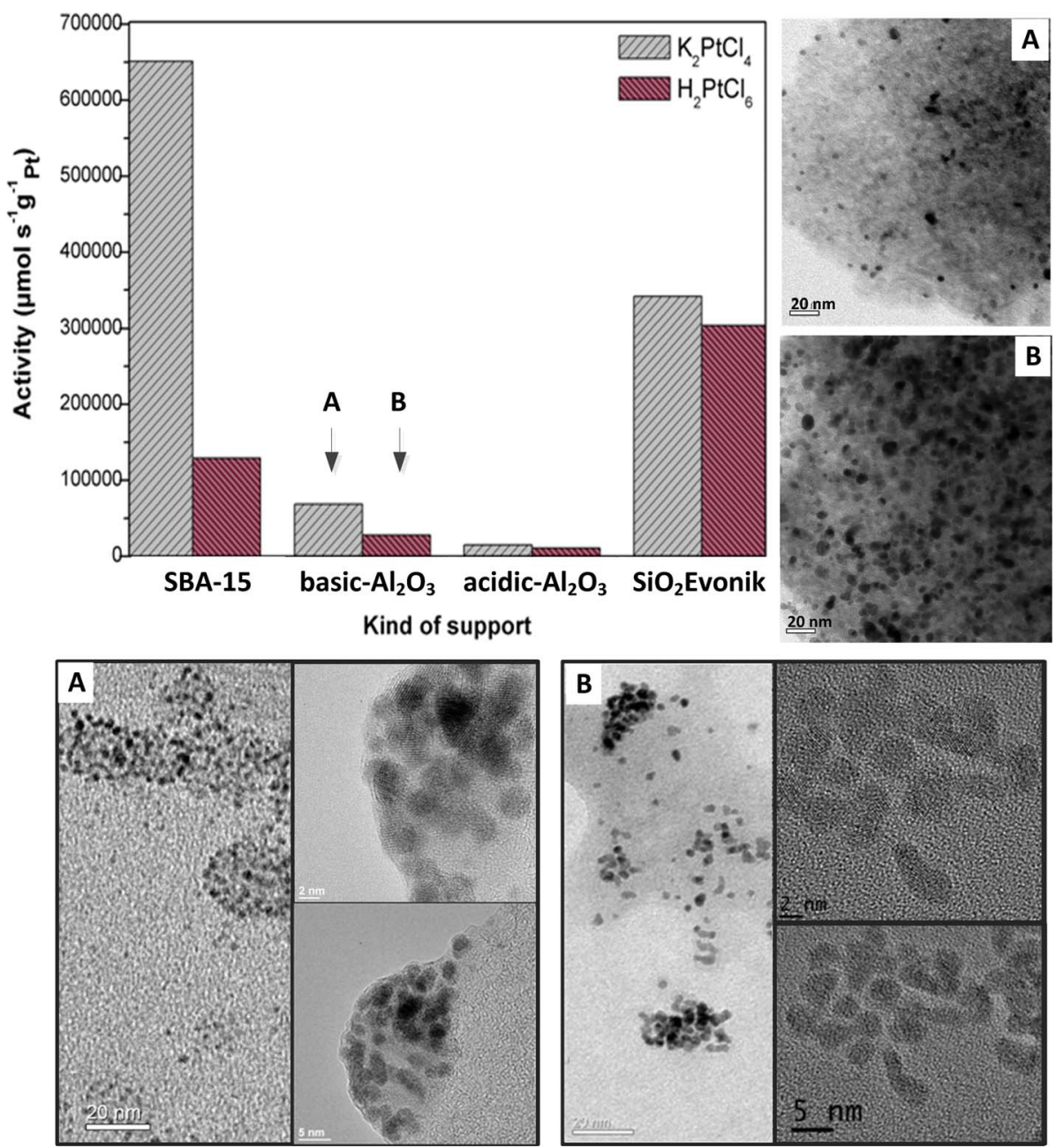

Fig. 7 Upper: activities of the supported Pt catalysts produced from different Pt precursors, $\mathrm{K}_{2} \mathrm{PtCl}_{4}(\mathrm{~A})$ and $\mathrm{H}_{2} \mathrm{PtCl}_{6}(\mathrm{~B})$, and the corresponding TEM images for basic $\mathrm{Al}_{2} \mathrm{O}_{3}$. Bottom: the corresponding HRTEM images of Pt nanodendrites inside reverse micelles. The branches of Pt dendrites were separated and always moving when they were exposed to high voltage electron beams during the TEM investigation.

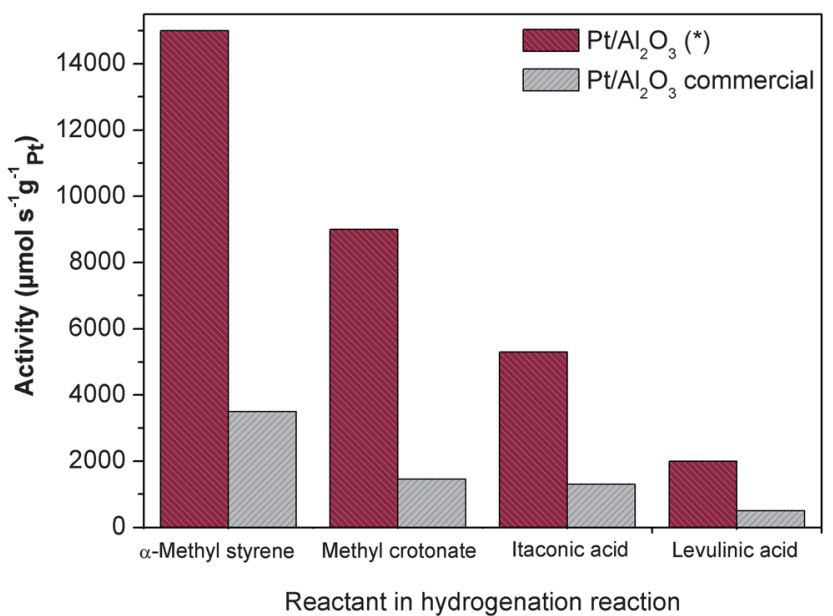

Fig. 8 Activity testing of $\mathrm{Pt} / \mathrm{Al}_{2} \mathrm{O}_{3}$ prepared via the thermo-destabilization method $\left(^{*}\right.$ ) compared to commercial $\mathrm{Pt} / \mathrm{Al}_{2} \mathrm{O}_{3}$ in hydrogenation reaction. All reactions were performed at $20^{\circ} \mathrm{C}$ and 1.1 bar, except levulinic acid hydrogenation: $70{ }^{\circ} \mathrm{C}$ and 1.3 bar. reduced with a weak reducing agent, the intermediate $\mathrm{Cl}_{3}{ }^{2-} \mathrm{Pt}-$ $\mathrm{Pt} \mathrm{Cl}_{3}{ }^{2-}$ dimer, subsequent dimer clusters and their aggregated higher linear $\mathrm{Pt}_{n} \mathrm{Cl}_{x}$ complexes are formed in the nucleation stage. ${ }^{15}$ We believe that these complexes are the genesis to produce nanodendrites.

\subsection{Catalytic testing with different substrates}

Additionally, as we have already shown in our previous paper, the activities of Pt catalysts prepared with our method and using hydrazine as the reductant are at least 4 times higher in AMS hydrogenation than those of the commercial Pt catalysts. If we compare now the Pt catalysts prepared by this optimized procedure with the commercial Pt catalysts, their activities are obviously much higher. Therefore, to verify the activity of our catalysts, we used our $\mathrm{Pt} / \mathrm{Al}_{2} \mathrm{O}_{3}$ as a representative catalyst to hydrogenate some other substrates such as methyl crotonate, itaconic acid and levulinic acid and then compared its performance to that of the commercial one. The results show that our Pt catalyst performs better with all substrates than the commercial one as depicted in Fig. 8. 


\begin{tabular}{|l|r|r|r|r|r|r|}
\hline RUN & $\mathbf{1}$ & $\mathbf{2}$ & $\mathbf{3}$ & $\mathbf{4}$ & $\mathbf{5}$ & $\mathbf{6}$ \\
\hline BET $\left(\mathrm{m}^{2} / \mathrm{g}\right)$ & 147 & 147 & 148 & 148 & 152 & 146 \\
\hline Activity $\left(\boldsymbol{\mu m o l} . \mathrm{s}^{-1} \cdot \mathrm{g}^{-1}\right)$ & 67000 & 69000 & 67000 & 68000 & 61000 & 65000 \\
\hline
\end{tabular}

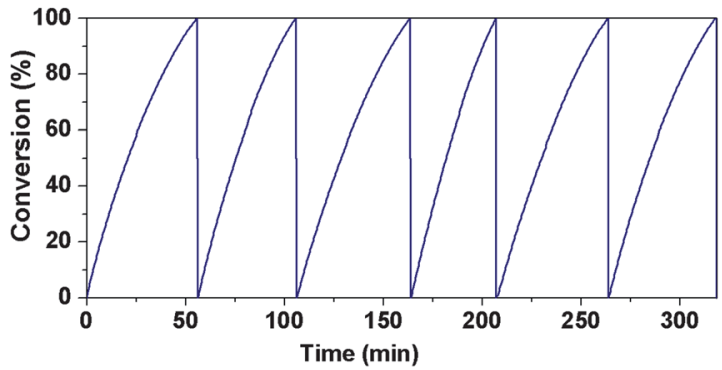

Fig. 9 Stability test of the $\mathrm{Pt} / \mathrm{Al}_{2} \mathrm{O}_{3}$ catalyst produced with ascorbic acid.

\subsection{Stability testing}

The aforementioned results show that the structure of $\mathrm{Pt}$ nanodendrites is irregular and low-coordinated atoms tend to be unstable. ${ }^{14}$ Because the stability is also an important parameter in the application of a catalyst, the stability of the supported Pt nanodendrites was tested. We took our $\mathrm{Pt} / \mathrm{Al}_{2} \mathrm{O}_{3}$ as a representative catalyst and used it over 6 runs (Fig. 9) of AMS hydrogenation. From the observed catalytic activities and BET surface areas, we found that the catalyst is significantly stable. This high durability indicates that the size and shape of Pt particles are considerably unchanged during reaction. This also implies that the interaction of the Pt particles with the alumina support is considerably strong. The platinum catalyst which we prepared with hydrazine as a reductant ${ }^{12}$ also shows excellent stability. However, we need to emphasize that our $\mathrm{Pt} / \mathrm{Al}_{2} \mathrm{O}_{3}$ catalyst, as we already mentioned in the previous paper, is more suitable for mild temperature reaction.

\section{Conclusion}

Here, we have demonstrated an optimized synthesis of supported Pt catalysts with thermo-destabilization of microemulsions by using AA as a reducing agent and $\mathrm{K}_{2} \mathrm{PtCl}_{4}$ as a metal precursor. As a weak reducing agent, ascorbic acid promotes a slow reduction of $\mathrm{Pt}$ ions and induces anisotropic growth which results in dendritic shape. This remarkable nanostructure is indeed highly attractive for catalytic applications because it has more edges and kinks. The intriguing aspect of the dendrite Pt nanoparticles discussed here is that the shape of the nanoparticles is a key factor in the high activity in spite of their bigger size. Accordingly, the lower catalytic activity of the smaller isotropic particles which is described in this work shows that the strategy of making smaller and smaller particles does not always lead to a better catalyst. In addition, the support material is also an important factor to improve the activity of the catalyst. We suggest that the interaction between the particles and the support material, which depends on the value of the zeta potential, influences the dispersion.

Although the test reactions given here refer to the double bond hydrogenations, similar catalytic performance is expectable with other important reactions under mild conditions.

\section{Acknowledgements}

The authors are grateful to the Ministry of National Education of Indonesia for financial support. Many thanks to Patrick Littlewood for helping in writing this paper, Sören Selve and Xing Huang for performing the TEM/HRTEM measurements, and Astrid Müller for assisting with the ICP measurements. This work is also a part of the DFG funded Cluster of Excellence "Unifying Concepts in Catalysis".

\section{References}

1 R. Narayanan and M. A. El-Sayed, Nano Lett., 2004, 4, 13431348.

2 V. Komanicky, H. Iddir, K.-C. Chang, A. Menzel, G. Karapetrov, D. Hennessy, P. Zapol and H. You, J. Am. Chem. Soc., 2009, 131, 5732-5733.

3 K. M. Bratlie, H. Lee, K. Komvopoulos, P. Yang and G. A. Somorjai, Nano Lett., 2007, 7, 3097-3101.

4 M. Subhramannia and V. K. Pillai, J. Mater. Chem., 2008, 18, 5858.

5 R. Narayanan and M. A. El-Sayed, J. Phys. Chem. B, 2005, 109, 12663-12676.

6 H. Song, F. Kim, S. Connor, G. A. Somorjai and P. Yang, J. Phys. Chem. B, 2005, 109, 188-193.

7 N. V. Long, N. D. Chien, T. Hayakawa, H. Hirata, G. Lakshminarayana and M. Nogami, Nanotechnology, 2010, 21, 035605.

8 Y. Xiong, B. J. Wiley and Y. Xia, Angew. Chem., Int. Ed., 2007, 46, 7157-7159.

9 T. S. Ahmadi, Z. L. Wang, T. C. Green, A. Henglein and M. A. El-Sayed, Science, 1996, 272, 1924-1925.

10 C. de M. Donegá, Chem. Soc. Rev., 2011, 40, 1512.

$11 \mathrm{~J}$. Xiao and L. Qi, Nanoscale, 2011, 3, 1383.

12 R. Y. Parapat, V. Parwoto, M. Schwarze, B. Zhang, D. S. Su and R. Schomäcker, J. Mater. Chem., 2012, 11605-11614.

13 F. Si, L. Ma, C. Liu, X. Zhang and W. Xing, RSC Adv., 2012, 2, 401.

14 A. R. Tao, S. Habas and P. Yang, Small, 2008, 4, 310-325.

15 T. Yao, S. Liu, Z. Sun, Y. Li, S. He, H. Cheng, Y. Xie, Q. Liu, Y. Jiang, Z. Wu, Z. Pan, W. Yan and S. Wei, J. Am. Chem. Soc., 2012, 134, 9410-9416.

16 L. Wang, C. Hu, Y. Nemoto, Y. Tateyama and Y. Yamauchi, Cryst. Growth Des., 2010, 10, 3454-3460.

17 L. Wang, H. Wang, Y. Nemoto and Y. Yamauchi, Chem. Mater., 2010, 22, 2835-2841.

18 Y. Song, Y. Yang, C. J. Medforth, E. Pereira, A. K. Singh, H. Xu, Y. Jiang, C. J. Brinker, F. van Swol and J. A. Shelnutt, J. Am. Chem. Soc., 2004, 126, 635-645.

19 J. Chen, T. Herricks and Y. Xia, Angew. Chem., Int. Ed., 2005, 44, 2589-2592.

20 M. Boutonnet, J. Kizling, V. Mintsa-Eya, A. Choplin, R. Touroude, G. Maire and P. Stenius, J. Catal., 1987, 103, 95-104.

21 D. Barkhuizen, I. Mabaso, E. Viljoen, C. Welker, M. Claeys, E. Van Steen and J. C. Q. Fletcher, Adv. Mater., 2006, 78, 1759-1769. 
22 D. Zhao, Q. Huo, J. Feng, B. F. Chmelka and G. D. Stucky, J. Am. Chem. Soc., 1998, 120, 6024-6036.

23 Q. Shen, L. Jiang, H. Zhang, Q. Min, W. Hou and J.-J. Zhu, J. Phys. Chem. C, 2008, 112, 16385-16392.

24 J. D. Hoefelmeyer, K. Niesz, G. A. Somorjai and T. D. Tilley, Nano Lett., 2005, 5, 435-438.

25 J. J. Spivey, G. W. Roberts, S. Rojas, S. Eriksson and M. Boutonnet, Catalysis, 2004, 17, 256-292.

26 A. Nerowski, M. Poetschke, M. Bobeth, J. Opitz and G. Cuniberti, Langmuir, 2012, 28, 7498-7504.

27 D. J. Bray, S. G. Gilmour, F. J. Guild, T. H. Hsieh, K. Masania and A. C. Taylor, J. Mater. Sci., 2011, 46, 6437-6452.

28 X. Ji, X. Song, J. Li, Y. Bai, W. Yang and X. Peng, J. Am. Chem. Soc., 2007, 129, 13939-13948.
29 H. Lee, S. E. Habas, S. Kweskin, D. Butcher, G. A. Somorjai and P. Yang, Angew. Chem., Int. Ed., 2006, 45, 7824-7828.

30 D. G. Duff, P. P. Edwards and B. F. G. Johnson, J. Phys. Chem., 1995, 99, 15934-15944.

31 L. C. Ciacchi, W. Pompe and A. De Vita, J. Am. Chem. Soc., 2001, 123, 7371-7380.

32 A. Henglein and M. Giersig, J. Phys. Chem. B, 2000, 104, 6767-6772.

33 A. Siani, Synthesis of Supported Nanoparticles for Catalytic Applications, ProQuest, 2007.

$34 \mathrm{~W}$. A. Spieker, J. Liu, J. T. Miller, A. J. Kropf and J. R. Regalbuto, Appl. Catal., A, 2002, 232, 219-235.

35 R. Ayala, E. S. Marcos, S. Díaz-Moreno, V. A. Solé and A. Muñoz-Páez, J. Phys. Chem. B, 2001, 105, 7588-7593. 